\title{
Evaluation of Student Core Drives on e-Learning during the Covid-19 with Octalysis Gamification Framework
}

\author{
Fitri Marisa $^{1}$ \\ Department of Informatic Engineering, Faculty of \\ Information and Communication Technology \\ Widyagama University of Malang \\ Universiti Teknikal Malaysia Melaka \\ Malang, Indonesia, Melaka, Malaysia \\ Sharifah Sakinah Syed Ahmad
Zeratul Izzah Mohd Yusoh \\ Faculty of Information and Communication Technology \\ Universiti Teknikal Malaysia Melaka \\ Melaka, Malaysia
}

\author{
Anastasia L Maukar ${ }^{4}$ \\ Industrial Engineering Department \\ President University, Jakarta, Indonesia \\ Ronald David Marcus ${ }^{5}$ \\ Faculty of Information Technology \\ University of Merdeka Malang, Malang, Indonesia \\ Anang Aris Widodo ${ }^{6}$ \\ Faculty of Information Technology \\ Merdeka University of Pasuruan, Pasuruan, Malang
}

\begin{abstract}
Learning activities during the Covid-19 pandemic were carried out with an online system even though in reality many institutions had not prepared their systems and infrastructure properly. Some e-learning media that are generally used based on survey results include $53.81 \%$ google classrooms combined with other applications that are not integrated with the institution's Learning Management System. This condition provides research opportunities to evaluate the effectiveness of online learning, especially how students are motivated to learn the method, where the results can be used as a reference in developing and refining the method. Based on many studies, that the gamification model can increase individual motivation in carrying out activities, this study uses a gamification octalysis framework to analyze the extent of the role of gamification in the learning process and measure the amount of student motivation in online learning activities. The evaluation results show that the conclusion of the Likert scale results in a "High" level, while the highest score is "Very High". As for the octalysis test scale, the average score of 6.5 on a scale of 1 to 10 . The conclusion from the results of this evaluation is that the motivation to learn e-learning during the Covid-19 period is quite high and has the potential to be developed. While the results of the Octalysis framework with 8 core drives are still average, for that we need innovation in E-learning which aims to increase student motivation based on Octalysis's 8 core drives. The results of this study recommend that gamification is needed to increase student learning motivation in order to improve learning outcomes.
\end{abstract}

Keywords-Gamificaton; education; Covid-19 pandemic; octalysis framework

\section{INTRODUCTION}

During the Covid-19 pandemic, the learning process in all countries was carried out using an online system [1],[2],[3]. At least, some fundamental problems affect the success of online learning, especially in the Covid-19 pandemic, one of them is the problem of limited infrastructure [2],[1]. However, with this emergency, many institutions have not prepared their systems and infrastructure properly, therefore, it is important to pay attention to this problem. [2],[1].

In conditions of limited infrastructure, the learning process is still carried out by utilizing available online learning technologies [4] on the internet such as Google classroom, moodle, zoom meeting, and others which are mostly not integrated with each other. From the results of a survey of 419 student respondents at several universities in Indonesia in August 2020, the data presented in Table I and Fig. 1. The highest number of categories is Google classroom mixed with other applications (53.81\%), for other media, was $25.71 \%$. Meanwhile, only $20.48 \%$ use e-learning applications, and this data represents the percentage of the availability of an integrated e-learning system provided by the institution (Learning Management System) [2],[1]. It can be inferred that the infrastructure which supports e-learning still needs improving.

The second problem is the decline in students' mental health during the lockdown period which has an impact on the low motivation of students towards the online learning system during Covid-19 pandemic. [5], [6], [7], [8]. However, this pandemic condition cannot be avoided, therefore efforts to increase user acceptance and motivation of online learning are also important [3]. Several studies [9] that observed the acceptance and motivation of teachers and students towards online learning have been carried out, such as [3] has observed student acceptance of online learning during a pandemic with observed parameters including attitude, influence, motivation, behavior control, and cognitive engagement [3]. The results of the analysis stated that the students preferred face-to-face learning [3]. 
TABLE I. PERCENTAGE OF E-LEARNING APPLICATION USED (BASED ON SURVEI ON AUGUST, 2020)

\begin{tabular}{|l|l|}
\hline Media & \% \\
\hline Google Classroom and others & 53.81 \\
\hline e-Learning Application & 20.48 \\
\hline Others & 25.71 \\
\hline
\end{tabular}

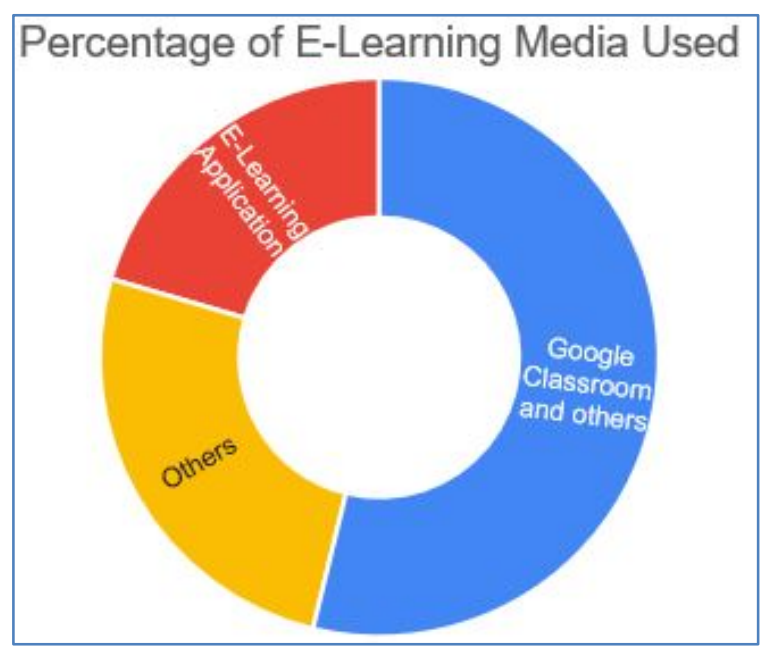

Fig. 1. Graph of Percentage of e-Learning media used (Based of Survei on August, 2020).

However, so far there has been no study that has a deeper evaluation of how students accept and perceive online learning without having to compare it to traditional learning. This is important to do considering that online learning is currently the only option in organizing learning during the Covid-19 pandemic. For this reason, efforts are needed to support the online learning system to get recommendations that can improve their performance. Although the development of online learning features in the future, it is necessary to develop knowledge pattern extraction and extraction [10] and a recommendation system [11],[12] from the resulting data, the extent to which users accept online learning itself is more fundamental. Exploring and providing recommendations about student perceptions is useful for re-evaluating online learning systems in the hope of knowing which parts should be improved or which should be maintained. This condition provides research opportunities to evaluate the effectiveness of online learning during this covid-19 pandemic. One of them is by proposing the concept of how to increase student learning motivation towards the method used, therefore that the results can be used as a reference for developing and improving existing methods. Based on many studies, gamification models can support increased motivation, and also measure it.[13],[14].

Gamification is one of the fields of science that comes from computer science became to multidiscipline science that adopts a game mechanism to be applied to a non-game system that aims to increase student motivation [15],[16]. In the field of education, gamification is also developed in a learning system that aims to increase student participation and motivation [13],[14]. Several gamification frameworks have been developed including MDA (Mechanics Dynamics

Sponsored by: Ministry of Research and Technology of the Republic of Indonesia RISTEK- BRIN.
Aesthetics), MDE (Emotional Mechanics Dynamics), and one of them is Octalysis [17].

The Octalysis framework was developed with the idea that each individual action is motivated by core drives that influence its action [18], [19]. Octalysis divides core drives into 8 types which are grouped into two groups, namely, the right brain (creativity) and the left brain (analytical) and White hat (top) and Black hat (bottom) [18], [19], [17]. With this potential, the Octalysis framework can measure and evaluate students' core drives against the online learning system that has been undertaken. The results of the further evaluation can provide recommendations to institutions in developing online learning to make it more optimal. This research contributes to the design method, analysis, and evaluation of the actual condition of the core drive experienced by users on a running system, especially in e-learning.

\section{LITERATURE REVIEW}

\section{A. e-Learning during Covid-19 Pandemic}

In this Covid-19 pandemic, online learning is the only solution for the learning process in all institution around the world [20], [3], [7], [1],[2],[3],[21]. The most emphasized thing on the characteristics of online learning is towards student independence and control is with students [20], for that effort related to it is important to do. However, common problems experienced in online learning today are limited infrastructure [1],[2], limited human resource capabilities [20], and low motivation [5], [6], [7], [8].

\section{B. Gamification}

Gamification is currently one of the technological trends that originated in the computer science and developed into a multidisciplinary science, by adopting game mechanisms to solve non-game system. [17], [16],[15]. Meanwhile, the focus that gamification wants to solve is increasing user acceptance, motivation and participation for the system being implemented [17], [16],[15]. Gamification has several frameworks where MDA (Mechanics, Dynamics, Aesthetics) is the basis of all existing frameworks in gamification. [22].

Fig. 2 described MDA framework, where Mechanics (M) are a set of rules / algorithms that cause a player to perform an action in a gamified system, and generally Mechanics are in the form of components such as levels, ratings, etc. [23], [22], [24]. Dynamics (D) is the movement of players resulting from the interaction process between players and mechanics. As an illustration, it can be said that if the points are mechanics, then the results of the points that the player gets after carrying out the rules set by the system are dynamics [23], [22], [24]. Aesthetics (A) is a component that deals with psychological aspects such as how players respond to game dynamics. Each player has a different response and Aesthetics is abstract. The MDE Aesthetics framework is also termed Emotional [23], [22], [24].

\section{Octalysis Gamification Framework}

The Gamification Octalysis framework was first invented by Yu-kai Chou, who based 8 core drives as a background or individual cause for action. [17],[18], [19]. Octalysis is the process of applying the core behavior drives that motivate a 
user to complete a task efficiently through an interactive experience. The Octalysis approach believes that no action will occur if there is no drive before [18], [19]. 8 core drives Octalysis is divided into 2 types of division, the first is right brain (creativity, expression) and left brain (analytical thinking) [17],[18],[19]. And the second group is grouped into 2 groups up (white hat) and bottom (black hat). White hat plays a role in positive motivation and brings a sense of meaning and a greater sense of control, while black hat acts as a negative impulse, but can inspire balance to achieve maximum results (Fig. 3) [17],[18], [19].

The description of the 8 core octalysis drives (Fig. 3) is as follows [18],[25]:

1) Epic meaning: Drive that plays a role in motivating to do work on the basis of the interests of the crowd above personal interests. A person is motivated to take action on the basis of being motivated that his actions will participate in completing a mission that is bigger than his own interests, and usually involves the interests of many people.

2) Development and accomplishment: Drive to take action on the basis of wanting to achieve an achievement. In general, someone takes an action because he hopes for a reward or something that he will have later. This drive is the easiest to expand compared to other 7 drives. Some of the mechanics that represent this drive include points, badges, and levels.

3) Empowerment of creativity and feedback: Drive for the creative process or they are looking for new things. Someone is motivated to take action for reasons of liking the freedom to create the object at hand and is involved in creative rposes. One of the mechanics that are often used in this drive is Evergreen Combos.

4) Ownership and possesion: This drive works by motivating ownership of something and trying to improve it. This drive is based on the idea that the more someone feels they own an object, the more he wants to maintain and improve it. Mechanics that are usually used in this drive include Avatar and virtual good.

5) Social influence and relatedness: This drive is motivated from social interaction so as to influence individual actions. This drive is based on the idea that a person takes action because of several things such as wanting to compete with others, wanting to cooperate with others, being inspired by other people, or because an object is connected to past memories. Mechanics involved in this drive include Group Quest, and mentorship.

6) Scarcity and impatience: This drive is driven by the motivation to take action simply because it is extremely rare, exclusive, or not immediately achievable. Someone is attracted to an object because it is exclusive and hard to find. Mechanics that are usually involved in these drives include countdown timers and price pacing.

7) Unpredictability and curiosity: A motivated drive to take action because something is difficult to predict. In other words, this drive works by provoking one's curiosity about the object. The more curious someone is, the more he will try to keep up. Mechanics who are usually involved in this drive include Rolling Reward, Sudden Reward.

8) Loss and avoinance: Drive that is motivated to take action for fear of missing an opportunity. This drive is in line with the "Unpredictability and Curosity" drive but the difference is that if this drive focuses on anticipating bad things and failures then someone tries to defend the object. The mechanics involved include Progress Loss, Status Quo Slots.

\section{Related Works}

In recent years gamification has emerged as a framework that also plays a role in the development of learning systems. [26], [27]. Gamification is applied to develop various learning materials, including: language, computers, statistics, and others [28],[29],[30]. The application of gamification is generally applied in learning design as a strategy to make learning methods more attractive [30], therefore increase students knowledge retention [31]. In another study, gamification was also shown to increase achievement motivation[32] and increase material absorption [29]. In its development, gamification in the learning method is collaborated with Artificial Intelligence to build a user personalization system so that the idea is expected to better accommodate user needs and increase motivation. [26].

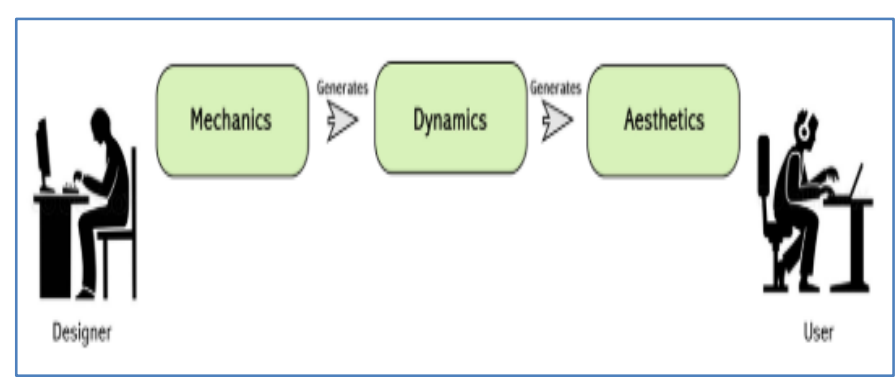

Fig. 2. MDA Framework [17].

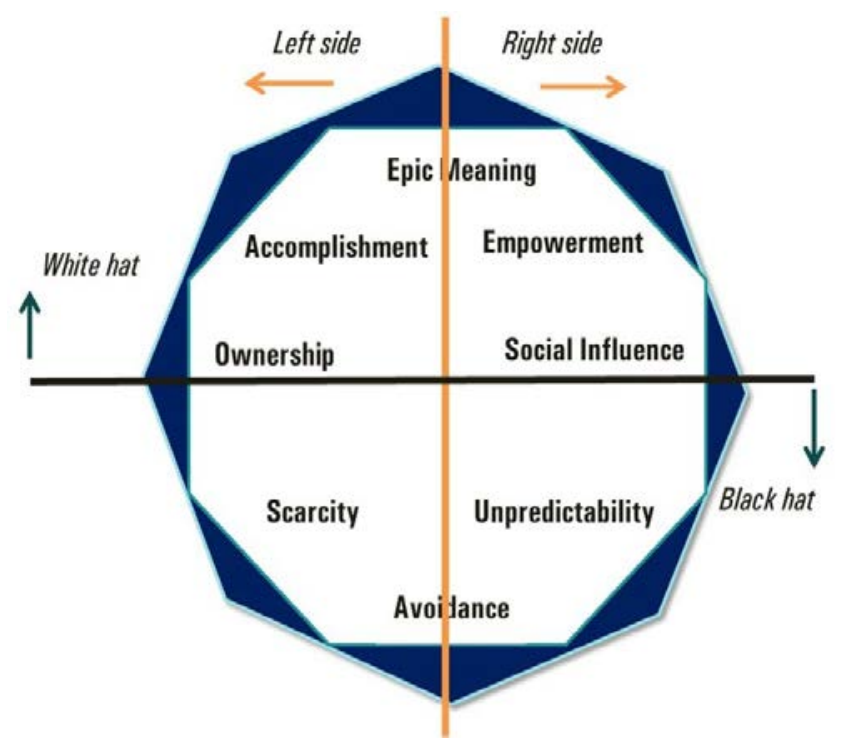

Fig. 3. Octalysis Framework [18]. 


\section{ReseARCh Methodology}

The research methodology described in Fig. 4.

1) Literature review: Literature studies are focused on collecting literature related to online learning, gamification theory in particular, the octalysis framework. The data were grouped using a questionnaire given to 419 student respondents in the provinces of East Java and West Java, Indonesia. The literature study also discusses the Likert scale and sample determination.

2) Determining of questionnaire: In this stage, the weight of the questionnaire is determined using a Likert scale [33] with four (4) criterias and making eight (8) questions, each of which represents 8 core drives.

3) Analysing each core drive: The stage of calculating each core drive with a Likert scale calculation and the results are categorized into four (4) levels of the range scale that have been determined based on the difference from the multiplication of the criteria weights and the number of respondents.

4) Analysing result measurement of likert scale test: In this stage, all the results of the Likert scale categorization of each core drive are filled in the table. This aims to find out and compare which core drives have a maximum or minimum value.

5) Converting and analysing result measurement of octalysis scale test: In this stage, the conversion process of the Likert scale calculation results of each core drive is converted into the octalysis test scale and the determination of the octagon pattern of the eight core drives that were tested. In this stage, an evaluation of the octagon pattern formed is also carried out compared to the octagon pattern which is the standard of achievement.

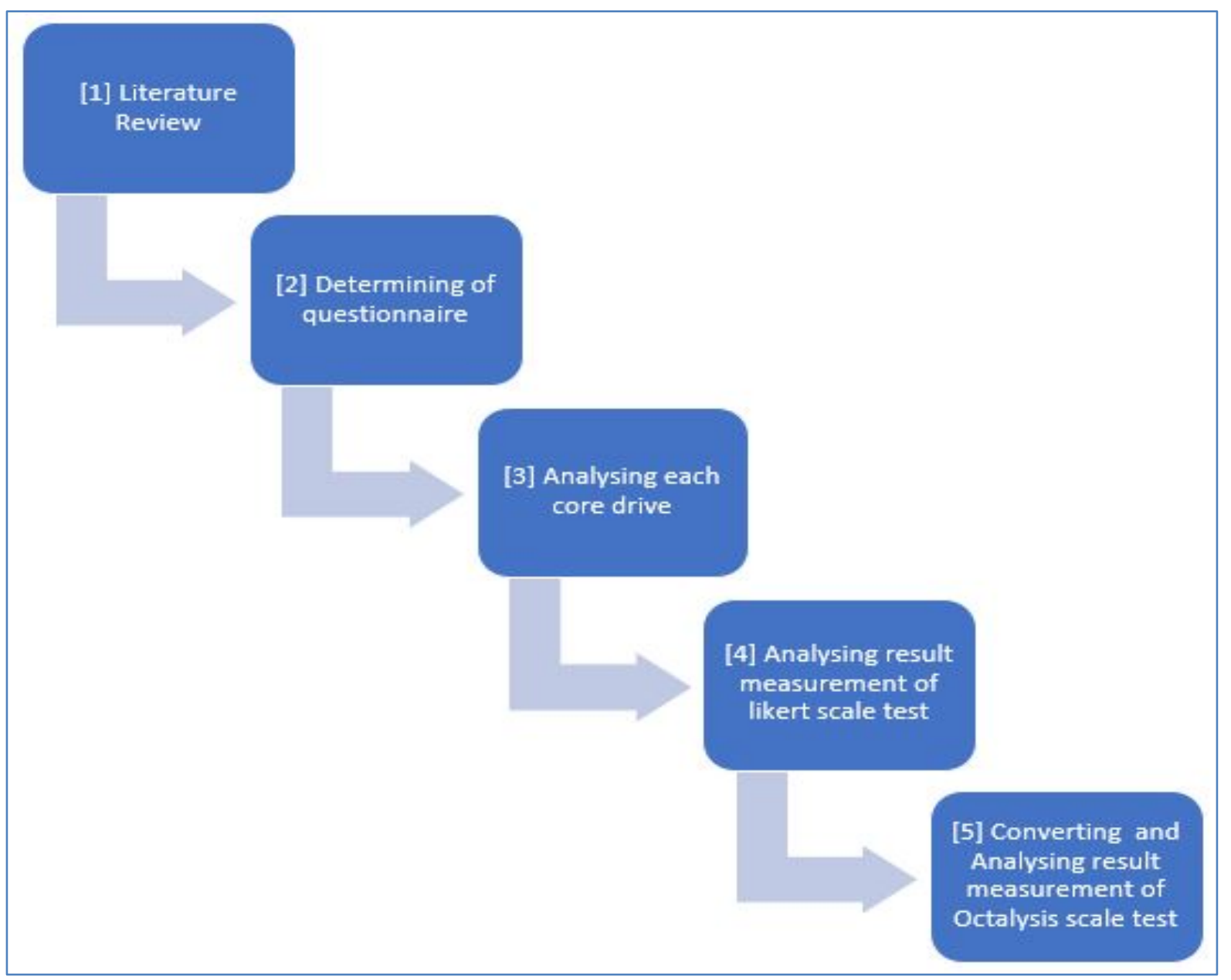

Fig. 4. Research Methodology. 


\section{RESUlts AND DisCUSSION}

\section{A. Determining of Questionnaire}

The analysis process begins by determining a questionnaire with eight questions representing each of the octalysis core drives. The questionnaire was filled with 419 respondents consisting of students spread across several campuses in the provinces of East Java and West Java, Indonesia. Questionnaires were distributed for two weeks in August 2020. The scale of measurement used a four-level Likert scale with the highest score of 4 and the lowest of 1 as in Table II.

Each core drives are grouped with a score multiplied by a weighted score. The results of all scores are totaled then grouped and given a predicate according to the range of the predicate score categories. The predicate for the category of score is determined based on the following calculations:

- Determine the lowest point of range, which is obtained from the multiplication of the number of respondents (N) with the lowest weight score (value $=1$ ), where $\mathrm{N}$ x $1(419$ x $1=419)$.

- Determine the highest point of range, which is obtained from the multiplication of the number of respondents $(\mathrm{N})$ with the highest weight score (value $=4$ ), where $\mathrm{N}$ x $4(419$ x $4=1676)$.

- Calculate the difference in range with the formula for the highest range minus the lowest range $(1676-419=$ 1257).

- Calculating the range value by dividing the range difference with the highest weight value (1257: $4=$ $314.25)$, rounded up to 314 . This value is used as a benchmark for the distance between levels in the measurement scale.

- Determine the level of the measuring scale consisting of 4 levels using the range of distances between levels that have been previously calculated at 314. The resulting measuring scale levels are as follows:

Very Low is 419 until 733,

Low is 734 until 1047,

High is 1048 until 1362,

Very High is 1363 until 1677.

\section{B. Analyzing Each Core Drive}

In this stage, the calculation and analysis of each core drives is carried out using Likert scale testing. The following are the measurement results of each core drives:

- Core Drive-1: Epic Meaning and Calling.

The question:

"The existence of the e-learning system used gives students the opportunity to participate in maintaining the stability of the learning process during the Covid-19 period"

Table III described the total score on the core drive Epic Meaning and Calling is 1279, which is in the "high" category.
This data has shown that students have a high enough awareness because they believe that taking good online learning during a pandemic is taking part in maintaining the stability of the learning process. This condition needs to be maintained, for example by providing a clear introduction to the objectives and benefits of following the material to be discussed.

- Core Drive-2: Development and Accomplishment.

The Question:

"The mechanism of the e-learning system that is used encourages students to improve their achievement"

Table IV described the total score for the Core Drive Development and Accomplishment is 1125, which is in the "high" category. This data has shown that students have a high enough awareness to achieve the targeted achievements. This condition needs to be maintained, for example by maintaining and increasing the reward of each achievement in material mastery.

- Core Drive-3: Empowerment of Creativity and Feedback.

The question:

"The existing e-learning system mechanism gives students the opportunity to freely choose the media to collect assignments or consult”

TABLE II. MEASUREMENT OF QUESTIONNAIRE

\begin{tabular}{|l|l|}
\hline Value & Declaration \\
\hline 1 & Very Weak \\
\hline 2 & Weak \\
\hline 3 & Strong \\
\hline 4 & Very Strong \\
\hline
\end{tabular}

TABLE III. RESUlt OF DATA ANALYZING CORE DRIVE-1 EPIC MEANING AND CALLING

\begin{tabular}{|l|l|l|l|}
\hline Answer & Number of Respondents & Value & Total \\
\hline Very Strong & 80 & 4 & 320 \\
\hline Strong & 289 & 3 & 867 \\
\hline Weak & 42 & 2 & 84 \\
\hline Very Weak & 8 & 1 & 8 \\
\hline$\Sigma$ & 419 & & 1279 \\
\hline
\end{tabular}

TABle IV. The Result of Data ANALyzing Core Drives-2 DEVELOPMENT AND ACCOMPLISHMENT

\begin{tabular}{|l|l|l|l|}
\hline Answer & Number of Respondents & Value & Total \\
\hline Very Strong & 37 & 4 & 148 \\
\hline Strong & 230 & 3 & 690 \\
\hline Weak & 135 & 2 & 270 \\
\hline Very Weak & 17 & 1 & 17 \\
\hline$\Sigma$ & 419 & & 1125 \\
\hline
\end{tabular}


Table $\mathrm{V}$ described the total score on the core drive- 3 Empowerment of Creativity and feedback is 1212, which is in the "high" category. This data has shown that students feel comfortable with online learning systems that provide flexibility in managing learning personalization. This condition needs to be maintained, for example by maintaining user personalization facilities on the online learning system.

\section{- Core Drive-4: Ownership and Possession}

The Question:

"The e-learning system mechanism used has user personalization facilities that motivate students to be responsible for the existence of their respective accounts".

Table VI described the total score on the core drive-4 ownership and possession is 1245 , which is in the "high" category. This data has shown that students feel ownership and try to maintain ownership in response to user personalization imposed by online learning. This condition needs to be maintained, for example by improving user personalization facilities on online learning systems so that the desire to maintain and improve personalization increases.

- Core Drive-5: Social Influence and Relatedness.

The question:

"The mechanism of the e-learning system that is used provides encouragement to be more competitive or collaborate between friends"

Table VII described the total score on the Core Drive-5 social influence and relatedness is 1154, which is in the "high" category. This data has shown that students feel the benefits of socializing with friends to support their progress in achieving success in learning. Students feel a connection with friends in increasing the motivation to compete and cooperate so that it automatically increases learning motivation. This condition needs to be maintained, for example by improving facilities or group assignments or increasing the intensity of tasks that are competitive among friends.

- Core Drive-6: Scarcity and Impatience

The question:

"The mechanism of the e-learning system that is used sometimes provides challenges that are not mandatory, for example in the form of time-limited quizzes that cause curiosity to try."

Table VIII described the total score on the core drive- 6 scarcity and impatience is 1154 , which is in the high category. This data shows that students have a high interest in one of the assignment models imposed by the online learning system which is intermittent and unscheduled. This model encourages students to be motivated to participate and not want to miss opportunities. This condition needs to be maintained, for example by maintaining the assignment model.

- Core Drive-7: Unpredictability and Curiosity.

The question:
"The e-learning system mechanism used includes a formative quiz facility which is announced unscheduled, which has encouraged students to frequently check their respective accounts for these opportunities."

Table IX shows the Result of Data Analyzing Core Drive7 unpredictability and Curiosity.

TABLE V. RESUlt OF DATA ANALYZING CORE DRIVE-3 EMPOWERMENT OF CREATIVITY AND FEEDBACK

\begin{tabular}{|l|l|l|l|}
\hline Answer & Number of Respondents & Value & Total \\
\hline Very Strong & 54 & 4 & 216 \\
\hline Strong & 274 & 3 & 822 \\
\hline Weak & 83 & 2 & 166 \\
\hline Very Weak & 8 & 1 & 8 \\
\hline$\sum$ & 419 & & 1212 \\
\hline
\end{tabular}

TABLE VI. RESUlt OF DATA ANALYZING CORE DRIVE-4 OWNERSHIP AND POSSESION

\begin{tabular}{|l|l|l|l|}
\hline Answer & Number of Respondents & Value & Total \\
\hline Very Strong & 52 & 4 & 208 \\
\hline Strong & 309 & 3 & 927 \\
\hline Weak & 52 & 2 & 104 \\
\hline Very Weak & 6 & 1 & 6 \\
\hline$\sum$ & 419 & & 1245 \\
\hline
\end{tabular}

TABLE VII. RESUlt OF DATA ANALYZING CORE DRIVE-5 SOCIAL INFLUENCE AND RELATEDNESS

\begin{tabular}{|l|l|l|l|}
\hline Answer & Number of Respondents & Value & Total \\
\hline Very Strong & 43 & 4 & 172 \\
\hline Strong & 252 & 3 & 756 \\
\hline Weak & 102 & 2 & 204 \\
\hline Very Weak & 22 & 1 & 22 \\
\hline$\sum$ & 419 & & 1154 \\
\hline
\end{tabular}

TABLE VIII. RESULT OF DATA ANALYZING CORE DRIVE-6 SCARCITY AND IMPATIENCE

\begin{tabular}{|l|l|l|l|}
\hline Answer & Number of Respondents & Value & Total \\
\hline Very Strong & 38 & 4 & 152 \\
\hline Strong & 253 & 3 & 759 \\
\hline Weak & 115 & 2 & 230 \\
\hline Very Weak & 13 & 1 & 13 \\
\hline$\sum$ & 419 & & 1154 \\
\hline
\end{tabular}

TABLE IX. Result of DAta ANALyzIng CoRe Drive-7 UNPREDICTABILITY AND CURIOSITY

\begin{tabular}{|l|l|l|l|}
\hline Answer & Number of Respondents & Value & Total \\
\hline Very Strong & 45 & 4 & 180 \\
\hline Strong & 274 & 3 & 822 \\
\hline Weak & 84 & 2 & 168 \\
\hline Very Weak & 16 & 1 & 16 \\
\hline$\sum$ & 419 & & 1186 \\
\hline
\end{tabular}


The total score on the core drive-7 unpredictability and curiosity is 1186, which is in the "high" category. This data has shown that students have a high level of anticipation for the assignments given. This condition supports students' readiness for learning materials and motivates them to always optimize their mastery of the material. This condition needs to be maintained, for example by maintaining the assignment model.

\section{- Core Drive-8: Loss and Avoidance}

The question:

"The mechanism of the e-learning system used includes achievement board facilities that can be known by all students, it has encouraged students to always maintain / increase levels so that they are not judged poorly in the learning environment."

Table $\mathrm{X}$ described the total score on the core drive-8 loss and avoidance is 1167, which is in the "high" category. This data has shown that students are trying to maintain a good social status so that this stimulus will increase motivation in maintaining good status, and will automatically have a positive impact on learning achievement. This condition needs to be maintained, for example by maintaining the assignment model and creating innovations in the form of maintaining status in the form of social facilities.

\section{A. Analyzing Result Measurement of Likert Scale}

The following is a comparison of all the results for the categories of 8 core drives that have been calculated (Table XI):

Therefore, from measuring the Likert scale of a questionnaire involving 8 core drives, it has been found that the motivational drive of 8 core drives is "high". Even though the research [3] has stated that students prefer traditional learning, the results of this study indicate that there is considerable potential to optimize online learning.

Meanwhile, the role of 8 core drives can explore more specifically about the diversity of students' motivations in taking online learning. The results of extracting data obtained are useful for evaluating and determining models for developing online learning systems to make them more targeted. From 8 core drives it is also possible to generate different or opposite category values, therefore, it is recommended that trials of online learning using the Octalysis framework are still needed.

TABLE X. Result of Data ANALyzING Core Drive-8 Loss AND AVOIDANCE

\begin{tabular}{|l|l|l|l|}
\hline Answer & Number of Respondents & Value & Total \\
\hline Very Strong & 51 & 4 & 204 \\
\hline Strong & 250 & 3 & 750 \\
\hline Weak & 95 & 2 & 190 \\
\hline Very Weak & 23 & 1 & 23 \\
\hline$\Sigma$ & 419 & & 1167 \\
\hline
\end{tabular}

\section{B. Converting and Analyzing Result Measurement of Octalysis Scale Test}

After knowing the results of the questionnaire analysis with the Likert scale, the optimal gamification results need to be tested with the octalysis scale. For testing with the octalysis scale, the value obtained from the questionnaire results must be converted into the octalysis scale rule. Each core drive has a value of 1 to 10 . The conversion steps to the octalysis scale are as follows:

- Determining the lowest point of range is obtained from the multiplication of the number of respondents $(\mathrm{N})$ with the lowest weight score (value $=1$ ), where $\mathrm{N} \times 1$ $(419 \times 1=419)$.

- Determine the highest point of range that has been obtained from the multiplication of the number of respondents $(\mathrm{N})$ with the highest weight score (value $=$ 4), where $\mathrm{N} \times 4(419 \times 4=1676)$.

- Calculate the difference in range with the formula for the highest range minus the lowest range (1676 - $419=$ 1257).

- Calculating the range value by dividing the range difference with the highest octalysis score (1257: $10=$ $125.7)$, rounded up to 125 . This value is used as a benchmark for the distance between levels in the measurement scale.

- Determine the level of a measuring scale consisting of 10 levels using the range of distances between levels that have been previously calculated at 125 . The resulting measuring scale levels are as follows:

Scale-1 is 419 until 544,

Scale-2 is 545 until 670,

Scale-3 is 671 until 797,

Scale-4 is 798 until 923,

Scale-5 is 924 until 1049,

Scale-6 is 1050 until 1175,

Scale-7 is 1176 until 1301,

Scale-8 is 1302 until 1427,

Scale-9 is 1428 until 1553,

Scale-10 is 1554 until 1679.

Furthermore, the octalysis score of 8 core drives can be determined based on the previously calculated values and adjusted for the level of the measuring scale (Table XI).

From the calculation of the octalysis scale, the octagon pattern is obtained as shown in Fig. 5 and Fig. 6.

In Fig. 5, each octalysis score generated in Table XII is measured and matched to the octalysis scale provided on the official octalysis website (https://yukaichou.com/octalysistool/) [34]. The measurement results can be seen in Fig. 5. 
TABLE XI. CONCLUSION OF LIKERT SCALE TEST FOR 8 CORE DRIVES

\begin{tabular}{|l|l|l|}
\hline \multicolumn{2}{|l|}{ Octalysis Core drive } & Category \\
\hline 1 & Epic Meaning and Calling & High \\
\hline 2 & Development and Accomplishment & High \\
\hline 3 & Empowerment and Creativity & High \\
\hline 4 & Ownership and Possession & High \\
\hline 5 & Social Influence and Relatedness & High \\
\hline 6 & Scarcity and Impatience & High \\
\hline 7 & Unpredictability and Curiosity & High \\
\hline 8 & Loss and Avoidance & High \\
\hline
\end{tabular}

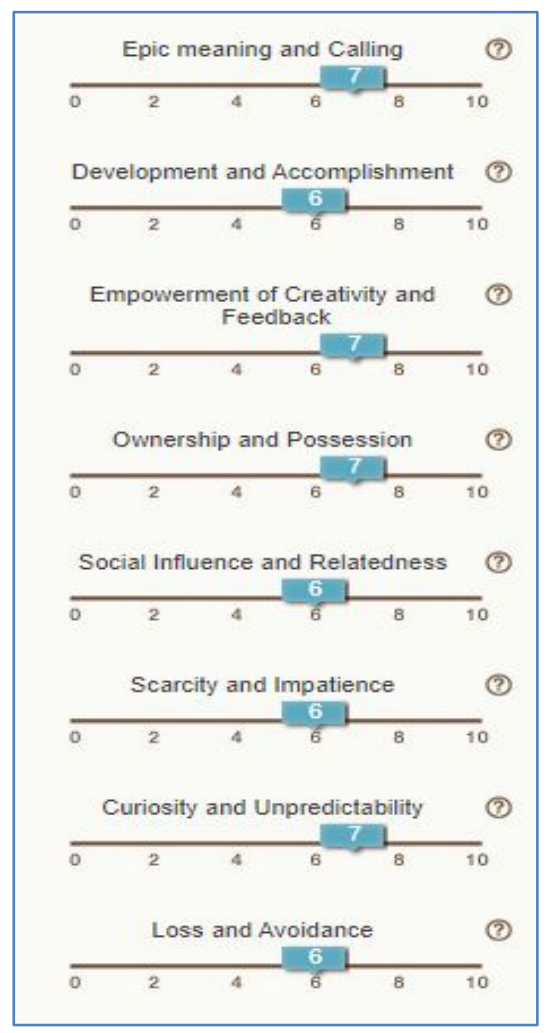

Fig. 5. Octalysis Scale.

In the octagon graph, you can see a visualization of the balance of core drives based on the questionnaire that has been generated. The octalysis value generated on the octalysis scale and octagon graph and the average manual count in Table XII is 340 which means that there is a good balance between Black Hat and White hat, and there is a balance between the left brain and the right brain. The balance of extrinsic and intrinsic motivation is also considered good.

\section{Gap Analysis of e-Learning during Covid-19}

In Table XIII, Table XIV, and Fig. 7, GAP data has been presented between the actual conditions and the desired conditions. For this reason, it is necessary to evaluate the causes of GAP according to the Octalysis framework.

1) Epic Meaning and Calling.

Target of statement : Very High
Target of Octalysis scale: 10

The existence of the e-learning system that is used provides the opportunity for students to participate in maintaining the stability of the learning process during the Covid-19 period optimally and consistently so that it can help strengthen the continuity and progress of e-learning.

\section{Actual statement: High}

\section{Actual Octalysis scale value: 7}

Students were motivated enough in their enthusiasm to play a role in the success of e-learning during the covid-19 period. However, students still need to improve and maintain the stability of their motivation because the actual target score has not reached the status of "Very High" and the value of the Octalysis scale still reaches 7 from the highest score of 10 .

\section{2) Development and Accomplishment.}

Target statement: Very High

Target Octalysis scale value: 10

The existence of the e-learning system that is used to motivate students to improve their achievement optimally, through lecturer feedback and an assessment system that can encourage students.

\section{Actual Statement: High}

Actual Octalysis scale value: 6

If you look at the value of the octalysis scale obtained, it shows that the feedback system and the assessment system applied do not really motivate students to improve achievement. Efforts should be made to provide feedback and a more attractive scoring system because the actual target value has not yet reached the "Very High" status and the Octalysis scale value still reaches 6 from the highest score of 10 .

TABLE XII. CONCLUSION OF OCTALYSIS

\begin{tabular}{|l|l|l|l|l|}
\hline \multicolumn{2}{|l|}{ Octalysis Core drive } & $\begin{array}{l}\text { Questionnaire } \\
\text { Score }\end{array}$ & $\begin{array}{l}\text { Octalysis } \\
\text { Scale }\end{array}$ & $\begin{array}{l}\text { Octalysis } \\
\text { Score }\end{array}$ \\
\hline 1 & $\begin{array}{l}\text { Epic Meaning and } \\
\text { Calling }\end{array}$ & 1279 & 7 & 49 \\
\hline 2 & $\begin{array}{l}\text { Development and } \\
\text { Accomplishment }\end{array}$ & 1125 & 6 & 36 \\
\hline 3 & $\begin{array}{l}\text { Empowerment and } \\
\text { Creativity }\end{array}$ & 1212 & 7 & 49 \\
\hline 4 & $\begin{array}{l}\text { Ownership and } \\
\text { Possession }\end{array}$ & 1245 & 7 & 49 \\
\hline 5 & $\begin{array}{l}\text { Social Influence and } \\
\text { Relatedness }\end{array}$ & 1154 & 6 & 36 \\
\hline 6 & Scarcity and Impatience & 1154 & 6 & 36 \\
\hline 7 & $\begin{array}{l}\text { Unpredictability and } \\
\text { Curiosity }\end{array}$ & 1186 & 7 & 49 \\
\hline 8 & Loss and Avoidance & 1167 & 6 & 36 \\
\hline Total score & \multicolumn{2}{|l}{} \\
\hline
\end{tabular}




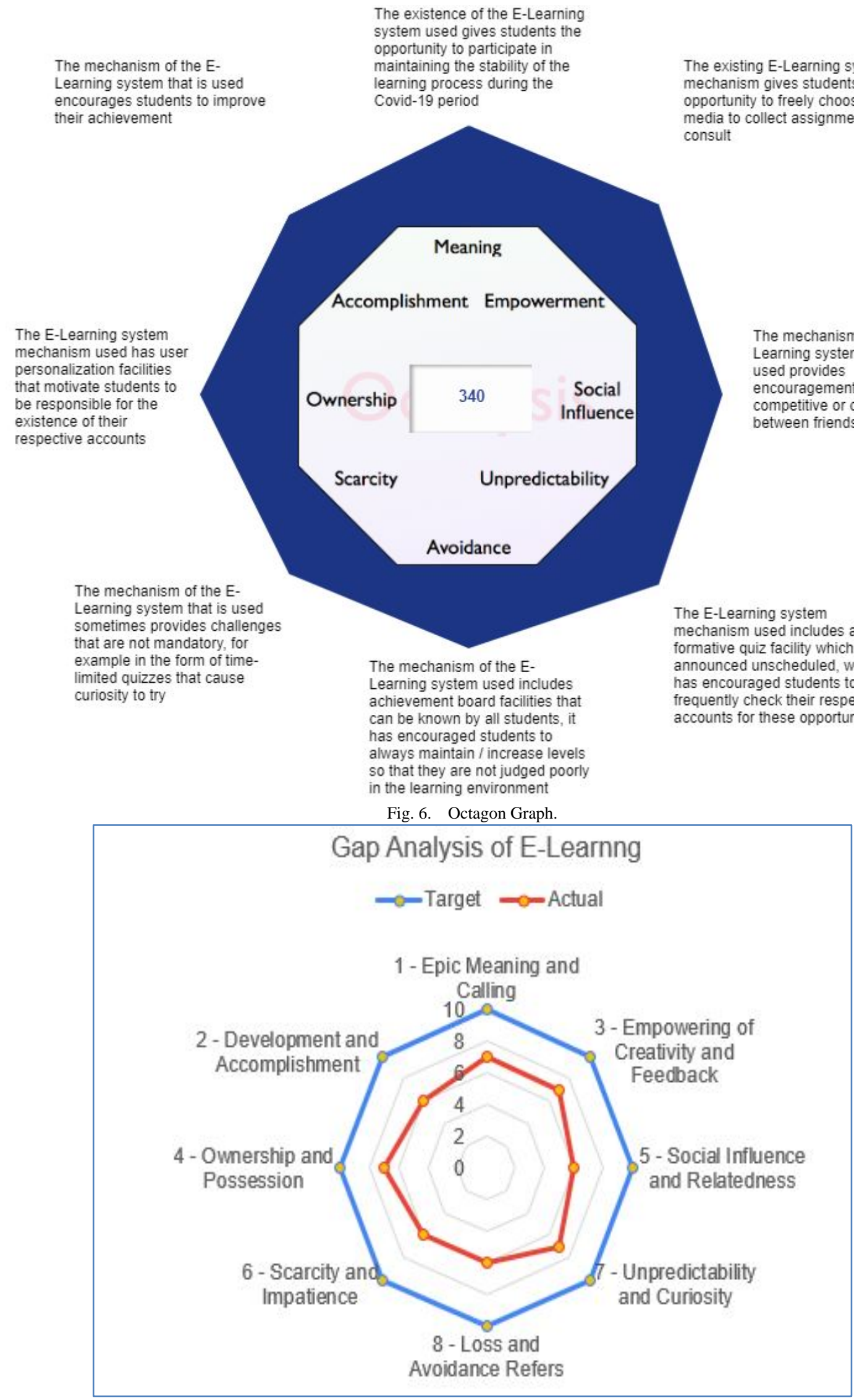

Fig. 7. The Graph of Gap Analysis. 
TABLE XIII. GAP ANALISIS OF LEARNING WITH QUESTIONNAIRE SCALE

\begin{tabular}{|l|l|l|l|}
\hline \multicolumn{2}{|l|}{ Octalysis Core drive } & Actual & Target \\
\hline 1 & Epic Meaning and Calling & High & Very High \\
\hline 2 & Development and Accomplishment & High & Very High \\
\hline 3 & Empowerment and Creativity & High & Very High \\
\hline 4 & Ownership and Possession & High & Very High \\
\hline 5 & Social Influence and Relatedness & High & Very High \\
\hline 6 & Scarcity and Impatience & High & Very High \\
\hline 7 & Unpredictability and Curiosity & High & Very High \\
\hline 8 & Loss and Avoidance & High & Very High \\
\hline
\end{tabular}

TABLE XIV. GAP ANALISIS OF LEARNING WITH OCTALYSIS SCALE

\begin{tabular}{|l|l|l|l|}
\hline \multicolumn{2}{|l|}{ Octalysis Core drive } & Actual & Target \\
\hline 1 & Epic Meaning and Calling & 7 & 10 \\
\hline 2 & Development and Accomplishment & 6 & 10 \\
\hline 3 & Empowerment and Creativity & 7 & 10 \\
\hline 4 & Ownership and Possession & 7 & 10 \\
\hline 5 & Social Influence and Relatedness & 6 & 10 \\
\hline 6 & Scarcity and Impatience & 6 & 10 \\
\hline 7 & Unpredictability and Curiosity & 7 & 10 \\
\hline 8 & Loss and Avoidance & 6 & 10 \\
\hline Average & 6.5 & \\
\hline
\end{tabular}

3) Empowerment of Creativity and Feedback.

Target statement: Very High

Target Octalysis scale value: 10

The flexibility of the e-learning system facilities, such as a media option for collecting assignments, provides comfort for students to use them optimally, thereby increasing optimal motivation for their use.

\section{Actual Statement: High}

\section{Actual Octalysis scale value: 7}

Based on the value of the octalysis scale obtained, it shows that e-learning facilities such as the freedom to choose media in collecting assignments quite motivating students to use them. However, this condition still needs to be improved because the actual target value has not yet reached the "Very High" status and the Octalysis scale value still reaches 7 from the highest value of 10 .

4) Ownership and Possession.

Target statement: Very High

Target Octalysis scale value: 10

User personalization in the e-learning system motivates students to maintain ownership and increase it so as to increase achievement in learning.

Actual Statement: High

\section{Actual Octalysis scale value: 7}

Based on the value of the octalysis scale obtained, it has shown that the user personalization facility on e-learning is sufficient to motivate students to care for and maintain account ownership. However, this condition still needs to be improved, for example by adding facilities to user personalization because the actual target value has not reached the status of "Very High" and the Octalysis scale value is still on a scale of 7 from the highest value of 10 .

5) Social Influence and Relatedness.

Target statement: Very High

Target Octalysis scale value: 10

The existence of the e-learning system motivates students to compete and collaborate with other friends in increasing achievement.

\section{Actual Statement: High}

Actual Octalysis scale value: 6

Based on the value of the octalysis scale obtained, it has shown that e-learning facilities still do not motivate students to compete and cooperate optimally. So, this condition needs to be improved because the actual target value has not yet reached the "Very High" status and the Octalysis scale value still reaches 6 from the highest value of 10 .

6) Scarcity and Impatience.

Target statement: Very High

Target Octalysis scale value: 10

The implementation of random assignment facilities in the e-learning system arouses students' curiosity. This condition motivates them not to be absent from doing their assignments and to improve their performance.

\section{Actual Statement: High}

Actual Octalysis scale value: 6

Based on the value of the octalysis scale obtained, it shows that the random assignment facility in the existing e-learning system still does not motivate students to follow it. So, this condition needs to be improved because the actual target value has not yet reached the "Very High" status and the Octalysis scale value still reaches 6 from the highest value of 10 .

7) Unpredictability and Curiosity.

Target statement: Very High

Target Octalysis scale value: 10

The implementation of the random assignment facility on the e-learning system generates an anticipatory attitude towards the given assignment. This condition motivates them not to be absent and to always check every notification of assignments so they don't miss their work.

Actual Statement: High

Actual Octalysis scale value: 7 
Based on the value of the octalysis scale obtained, it shows that the random assignment facility in the applicable elearning system is quite motivating students to anticipate the random assignment given. However, this condition needs to be improved because the actual target value has not yet reached the "Very High" status and the Octalysis scale value still reaches 7 from the highest value of 10 .

8) Loss and Avoidance.

Target statement: Very High

Target Octalysis scale value: 10

The implementation of the achievement board sharing facility provides a stimulus to students to always show their best performance so that they are not judged poorly in their learning environment. This condition motivates them to always maintain and improve their performance.

Actual Statement: High

Actual Octalysis scale value: 6

Based on the value of the octalysis scale obtained, it has shown that the achievement board facility imposed by the elearning system is not sufficient to motivate students to encourage students to maintain and improve their achievement. So, this condition needs to be improved because the actual target value has not yet reached the "Very High" status and the Octalysis scale value still reaches 6 from the highest value of 10 .

\section{RECOMMENDATIONS}

Based on the results of the GAP evaluation of online learning conducted by questionnaire and octalysis scale analysis, it is suggested that recommendations based on 8 core drives are as follows:

1) As an emergency system, the potential for "Epic Meaning and Calling" is quite good in the applicable elearning. This potential needs to be maintained and increased because it involves a large amount of intrinsic motivation. Students are motivated to involve themselves in the e-learning system during the Covid-19 period because their involvement can take part in the mission of successful learning in an emergency. With the value of the "High" scale and the octalysis scale of 7, this condition still needs to be improved, such as providing an overview and explanation of the objectives of each material to be studied, so that students understand the purpose of studying.

2) e-Learning efforts to provide a stimulus that can motivate achievement have been implemented, but this has not been able to motivate students to improve achievement optimally. The feedback and assessment system model that is applied needs to be evaluated and developed to make it more attractive. Therefore, adding variations in the assessment model is needed so that students have a choice in choosing a model. The achievement presentation model can adopt the types of gamification mechanics such as points, levels, badges, and leaderboards to package achievements in the hope that it can further improve students to increase achievement.
With the value of the "High" scale and the octalysis scale of 6, this condition still needs to be explored.

3) The flexibility to use e-learning media plays a role in increasing drives "Empowerment and Creativity". The current e-learning has implemented facilities such as the freedom to collect assignments, and this is enough to attract students as evidenced by the value of the "High" scale. However, this method needs to be developed considering the octalysis scale still reaches a value of 7. "Empowerment and Creativity" is based on the idea that people not only need a way to express creativity, but they need a way to see the results of that creativity, receive feedback, and respond in turn. Several mechanics need to be tried out to improve this drive, such as blank fills combos to give students the opportunity to write free notes, instant feedback to give students the opportunity to give feedback on the material being discussed.

4) The application of user personalization facilities in the applicable e-learning system has created sufficient student comfort, as evidenced by the acquisition of a "High" questionnaire scale value and an octalysis scale value of 7 . However, this condition still needs to be improved again considering the achievement of the octalysis value and the level of the questionnaire scale has not reached the highest point. "Ownership and Possession is based on encouragement in which users are motivated because they feel they have something. When a player has a sense of belonging, he automatically wants to make what he has better and even more. For this reason, exploration of mechanics related to this drive needs to be explored, such as applying avatars as student identities according to achievement and character, or holding "virtual good" to increase ownership.

5) The current existence of e-learning is not enough to generate motivation for cooperation or competition between students. This is evidenced by the octalysis scale obtained by 6 while the highest score is 10 . Drive "Social Influence and Relatedness" is based on the encouragement of someone to do something because it is inspired by others, both in terms of competition and cooperation. It is necessary to explore possible methods to generate this thrust. Some mechanics that need to be tried include group quests, friending, and social treasures, each of which are mechanics.

6) e-Learning that has been running has implemented a facility that generates a "Scarcity and Impatience" drive, for example the facility to provide random assignments that are unscheduled in nature. In fact, this is not enough to encourage students to improve this drive, which is evidenced by the value of the Octalysis scale which is still in the range of 6 . The "Scarcity and Impatience" drive is based on the idea that something that is rare and difficult to obtain motivates individuals to want to have. Several mechanics that can be adopted in e-learning include "countdown timer" and "Appointment Dynamics". These two mechanics are used in elearning for assignment systems with the hope of motivating students to always follow them. 
7) The "Unpredictable and Curiosity" drive in e-learning has been implemented in the form of random assignments. Its existence is sufficient to motivate students, as evidenced by the octalysis scale value is in the range of 7 , but this still needs to be improved to reach 10 . This drive uses the same facilities as the 6th drive "Scarcity and Impatience" but the difference is from the point of view of the drive that is raised. This drive is based on the individual always thinking about what will happen next, thus encouraging him to always anticipate something that will happen that will come in his favor. The task systems that generate these drives need to be explored more deeply. This mechanic drive model that can be applied in e-learning includes "random reward", "rolling reward" both of which can be applied in the assessment and assignment systems.

8) Drive "Loss and Avoidance" in the current e-learning system has been applied in the form of sharing achievement boards with the hope that it can motivate students to anticipate by keeping their achievements so they are not judged negatively in their environment. However, this drive is not optimally absorbed, as evidenced by the Octalysis scale value of 6 from the highest scale of 10 . This drive is based on individual efforts to avoid something negative, so someone takes anticipatory action against the conditions at hand. In the e-learning system, the developer can adopt the mechanics that are usually used in this drive such as "Progress Loss" and "Status Quo Slot" in the scoring system with the hope that students can be motivated to take anticipatory action against the actual conditions that occur.

\section{CONCLUSION AND FUTURE WORKS}

In general, the implementation of e-learning during the Covid-19 period, especially in Indonesia, was quite acceptable to students, as evidenced by the results of the GAP analysis on the questionnaire analysis on a "high" scale while the highest achievement was "very high". However, if motivation is analyzed more deeply using the Octalysis scale, the average results are in the range of 6.5 from the scale range 1 to 10 . Therefore, on the one hand, this actual condition has the potential to be developed, but more innovative development is needed to generate student core drives so that it will increase motivation to learn.

Gamification can optimally support the e-learning system, if it is taken seriously. Because in reality society really needs refreshment, something new that can make an object interesting and that continues to develop [35]. The Octalysis framework provides a choice of mechanics to explore learning models that can generate and enhance core drives more optimally. Each core drive has provided recommendations and guides available on the official website https://yukaichou.com/octalysis-tool/[34] which can be accessed freely as a standard. Several mechanics in accordance with the needs of the system are adopted and explored, therefore, that it is expected to support the optimization of students' core drives for e-learning.

\section{ACKNOWLEDGMENT}

All Authors would like to thank all who have gave contributions to this research starting from DRPM KEMENRISTEK BRIN of Ministry of Research and Technology \& Higher Education, Indonesia; Universiti Teknikal Malaysia Melaka (UTeM); Malaysia, Widyagama University of Malang, Indonesia; President University, Indonesia; Indonesia and all colleagues who have contributed for valuable directions and suggestions to strength this quality paper.

\section{REFERENCES}

[1] L. Mishra, D. T. Gupta, and D. A. Shree, "Online Teaching-Learning in Higher Education during Lockdown Period of COVID-19 Pandemic," Int. J. Educ. Res. Open, p. 100012, 2020, doi: 10.1016/j.ijedro.2020.100012.

[2] A. Sharma, S. B. Borah, and A. C. Moses, "Responses to COVID-19: The Role of Governance, Healthcare Infrastructure, and Learning from Past Pandemics,” J. Bus. Res., 2020, doi: 10.1016/j.jbusres.2020.09.011.

[3] A. Patricia, “College Students' Use and Acceptance of Emergency Online Learning Due to COVID-19,” Int. J. Educ. Res. Open, p. 100011, 2020, doi: 10.1016/j.ijedro.2020.100011.

[4] T. Y. Chang et al., "Innovation of dental education during COVID-19 pandemic,” J. Dent. Sci., no. 155, 2020, doi: 10.1016/j.jds.2020.07.011.

[5] E. M. Aucejo, J. French, M. P. U. Araya, and B. Zafar, "The Impact of COVID-19 on Student Experiences and Expectations: Evidence from a Survey.," J. Public Econ., vol. 191, p. 104271, 2020, doi: 10.1016/j.jpubeco.2020.104271.

[6] D. Marques de Miranda, B. da Silva Athanasio, A. Cecília de Sena Oliveira, and A. C. Simoes Silva, "How is COVID-19 pandemic impacting mental health of children and adolescents?,” Int. J. Disaster Risk Reduct., vol. 51, no. September, p. 101845, 2020, doi: 10.1016/j.ijdrr.2020.101845.

[7] N. Hasan and Y. Bao, “Impact of 'e-Learning crack-up' perception on psychological distress among college students during COVID-19 pandemic: A mediating role of 'fear of academic year loss,"” Child. Youth Serv. Rev., vol. 118, no. July, p. 105355, 2020, doi: 10.1016/j.childyouth.2020.105355.

[8] B. Oosterhoff, C. A. Palmer, J. Wilson, and N. Shook, “Adolescents' Motivations to Engage in Social Distancing During the COVID-19 Pandemic: Associations With Mental and Social Health,” J. Adolesc. Heal., vol. 67, no. 2, pp. 179-185, 2020, doi: 10.1016/j.jadohealth.2020.05.004.

[9] M. Saefi et al., "Survey data of COVID-19-related knowledge, attitude, and practices among indonesian undergraduate students,” Data Br., vol. 31, p. 105855, 2020, doi: 10.1016/j.dib.2020.105855.

[10] F. Marisa, S. S. S. Ahmad, Z. I. M. Yusof, Fachrudin, and T. M. A. Aziz, "Segmentation model of customer lifetime value in Small and Medium Enterprise (SMEs) using K-Means Clustering and LRFM model,” Int. J. Integr. Eng., vol. 11, no. 3, pp. 169-180, 2019, doi: 10.30880/ijie.2019.11.03.018.

[11] F. Marisa, S. Sakinah, S. Ahmad, Z. Izzah, M. Yusoh, and T. M. Akhriza, "Performance Comparison of Collaborative-Filtering Approach with Implicit and Explicit Data,” Int. J. Adv. Comput. Sci. Appl., vol. 10, no. 10, pp. 110-116, 2019, [Online]. Available: https://thesai.org/Downloads/Volume10No10/Paper_16Performance_Comparison_of_Collaborative_Filtering_Approach.pdf.

[12] I. Istiadi, F. Rofii, A. Qustoniah, F. Marisa, and G. D. Putra, "Online Expert System for Consultation Services using a Mobile,” J. Teknol., vol. 78, no. 6-3, pp. 41-46, 2016, [Online]. Available: https://journals.utm.my/index.php/jurnalteknologi/article/view/8926.

[13] M. C. Carnero, "Fuzzy multicriteria models for decision making in gamification,” Mathematics, vol. 8, no. 5, 2020, doi: 10.3390/MATH8050682.

[14] S. A. A. Freitas, A. R. T. Lacerda, P. M. R. O. Calado, T. S. Lima, and E. D. Canedo, "Gamification in education: A methodology to identify 
student's profile,” Proc. - Front. Educ. Conf. FIE, vol. 2017-Octob, no. December, pp. 1-8, 2017, doi: 10.1109/FIE.2017.8190499.

[15] J. Kasurinen and A. Knutas, "Publication trends in gamification: A systematic mapping study,” Comput. Sci. Rev., vol. 27, pp. 33-44, 2018, doi: 10.1016/j.cosrev.2017.10.003.

[16] A. M. Toda, R. M. C. do Carmo, A. P. da Silva, I. I. Bittencourt, and S. Isotani, "An approach for planning and deploying gamification concepts with social networks within educational contexts,” Int. J. Inf. Manage., vol. 46, no. October 2018, pp. 294-303, 2019, doi: 10.1016/j.ijinfomgt.2018.10.001.

[17] J. Landsell and E. Hägglund, Towards a Gamification Framework: Limitations and opportunities when gamifying business processes. 2016.

[18] Y. Chou, Actionable Gamification, Beyond Points, Badges, and Leaderboards - Google Play. 2019.

[19] Y.-K. Chou, Actionable gamification: Beyond points, badges, and leaderboards. 2016.

[20] R. Radha, K. Mahalakshmi, V. S. Kumar, and A. R. Saravanakumar, "ELearning during Lockdown of Covid-19 Pandemic: A Global Perspective,” Int. J. Control Autom., vol. 13, no. 4, pp. 1088-1099, 2020.

[21] Mailizar, A. Almanthari, S. Maulina, and S. Bruce, "Secondary school mathematics teachers' views on e-learning implementation barriers during the COVID-19 pandemic: The case of Indonesia," Eurasia J. Math. Sci. Technol. Educ., vol. 16, no. 7, 2020, doi: 10.29333/EJMSTE/8240.

[22] K. Robson, K. Plangger, J. H. Kietzmann, I. McCarthy, and L. Pitt, "Is it all a game? Understanding the principles of gamification,” Bus. Horiz., vol. 58, no. 4, pp. 411-420, 2015, doi: 10.1016/j.bushor.2015.03.006.

[23] Risal, "Pembangunan Gamification ( Game Mechanics ) Framework," 2013.

[24] P. H. Bachtiar, W. S. Wardhono, and T. Afirianto, "Pendekatan MDA Framework Pada Pengembangan Permainan Baby Care Augmented Reality dengan Outfit Marker,” J. Pengemb. Teknol. Inf. dan Ilmu Komput. Univ. Brawijaya, vol. 2, no. 12, 2018.

[25] F. Marisa, S. Sakinah, S. Ahmad, and Z. I. Mohd, "Analysis Of Relationship CLV with 8 Core Drives Using Clustering K-Means and Octalysis Gamification Framework,” J. Theor. Appl. Inf. Technol., vol. 98, no. 20, pp. 3151-3164, 2020, [Online]. Available: http://www.jatit.org/volumes/Vol98No20/6Vol98No20.pdf.
[26] M. Urh, G. Vukovic, E. Jereb, and R. Pintar, "The Model for Introduction of Gamification into E-learning in Higher Education,” in Procedia - Social and Behavioral Sciences, 2015, vol. 197, no. February, pp. 388-397, doi: 10.1016/j.sbspro.2015.07.154.

[27] L. Aguiar-Castillo, L. Hernández-López, P. De Saá-Pérez, and R. PérezJiménez, "Gamification as a motivation strategy for higher education students in tourism face-to-face learning,” J. Hosp. Leis. Sport Tour. Educ., vol. 27, no. September, 2020, doi: 10.1016/j.jhlste.2020.100267.

[28] N. L. Mingoc, E. Louwe, and R. Sala, "Design and Development of Learn Your Way Out: A Gamified Design and Development of Learn Your Way Out: A Gamified Content for Basic Java Computer Programming," in Procedia Computer Science, 2019, vol. 161, pp. 1011-1018, doi: 10.1016/j.procs.2019.11.211.

[29] D. Kayimbașioğlu, B. Oktekin, and H. Haci, "Integration of Gamification Technology in Education," in Procedia Computer Science, 2016, vol. 102, no. August, pp. 668-676, doi: 10.1016/j.procs.2016.09.460.

[30] N. Z. Legaki, N. Xi, J. Hamari, K. Karpouzis, and V. Assimakopoulos, "The effect of challenge-based gamification on learning: An experiment in the context of statistics education,” Int. J. Hum. Comput. Stud., vol. 144, no. June, 2020, doi: 10.1016/j.ijhcs.2020.102496.

[31] L. M. Putz, F. Hofbauer, and H. Treiblmaier, "Can gamification help to improve education? Findings from a longitudinal study,” Comput. Human Behav., vol. 110, no. November 2019, p. 106392, 2020, doi: 10.1016/j.chb.2020.106392.

[32] G. P. Kusuma, E. K. Wigati, Y. Utomo, and L. K. Putera Suryapranata, "Analysis of Gamification Models in Education Using MDA Framework,” in Procedia Computer Science, 2018, vol. 135, pp. 385392, doi: 10.1016/j.procs.2018.08.187.

[33] V. H. Pranatawijaya, W. Widiatry, R. Priskila, and P. B. A. A. Putra, "Penerapan Skala Likert dan Skala Dikotomi Pada Kuesioner Online," J. Sains dan Inform., vol. 5, no. 2, p. 128, 2019, doi: 10.34128/jsi.v5i2.185.

[34] Y.-K. Chou, “Gamification Framework," Gamification Framework, 2020. https://yukaichou.com/gamification-examples/octalysis-completegamification-framework/.

[35] G. Wang and A. Y. Ariyanto, "Gamification: Strengthening The Relationship,” J. Theor. Appl. Inf. Technol., vol. 97, no. 17, pp. 44904507, 2019. 